\title{
Crusted Scabies Presenting as White Superficial Onychomycosislike Lesions
}

\author{
Nardo Zaias, MD; Sandra Escovar, MD; Ploypailin Jungcharoensukying, MD
}

\section{PRACTICE POINTS}

- Crusted scabies is asymptomatic; therefore, any white lesion at the surface of the nail should be scraped and examined with potassium hydroxide.

- Immunosuppressed patients are at risk for infection.

\section{To the Editor:}

We report the case of an 83-year-old male nursing home resident with a history of end-stage renal disease who presented with multiple small white islands on the surface of the nail plate, similar to those seen in white superficial onychomycosis (Figure 1). Minimal subungual hyperkeratosis of the fingernails also was observed. Three digits were affected with no toenail involvement. Wet mount examination with potassium hydroxide $20 \%$ showed a mite (Figure 2A) and multiple eggs (Figure 2B). Treatment consisted of oral ivermectin $3 \mathrm{mg}$ immediately and permethrin solution $5 \%$ applied under occlusion to each of the affected nails for 5 consecutive nights, which resulted in complete clearance of the lesion on the nail plate after 2 weeks.

Crusted scabies was first described as Norwegian scabies in 1848 by Danielsen and Boeck, ${ }^{1}$ and the name was later changed to crusted scabies in 1976 by Parish and Lumholt ${ }^{2}$ because there was no inherent connection between Norway and Norwegian scabies. It is a skin infestation of Sarcoptes scabiei var hominis and more commonly is seen in immunocompromised individuals such as the

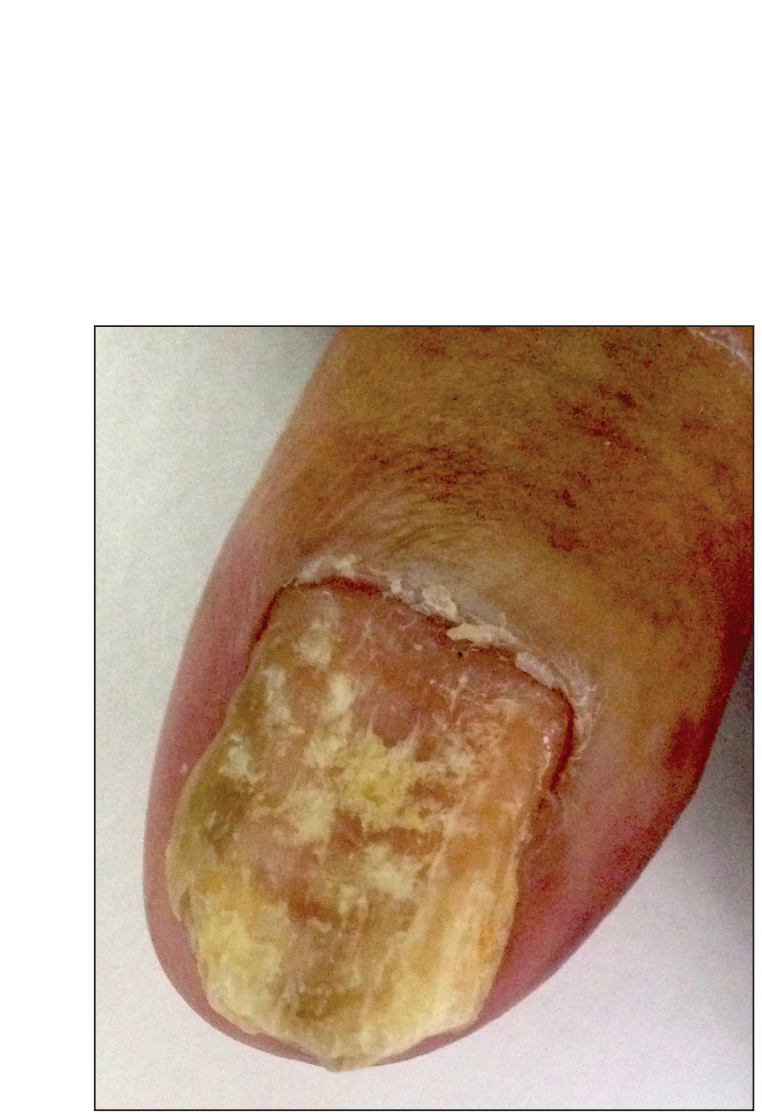

FIGURE 1. Crusted scabies. Nail plate with multiple small superficial white islands with mild subungual hyperkeratosis.

elderly and malnourished patients as well as those with diabetes mellitus and alcoholism. ${ }^{3,4}$ Patients typically present with widespread hyperkeratosis, mostly involving the palms and soles. Subungual hyperkeratosis and nail dystrophy also can be seen when nail involvement is present, and the scalp rarely is involved. ${ }^{5}$ Unlike common

From the Greater Miami Skin \& Laser Center at Mount Sinai Medical Center, Miami Beach, Florida.

The authors report no conflict of interest.

Correspondence: Nardo Zaias, MD, Mount Sinai Medical Center, Greater Miami Skin \& Laser Center, 4308 Alton Rd, Ste 750, Miami Beach, FL 33140 (nardozaias@aol.com).

doi:10.12788/cutis.0190 

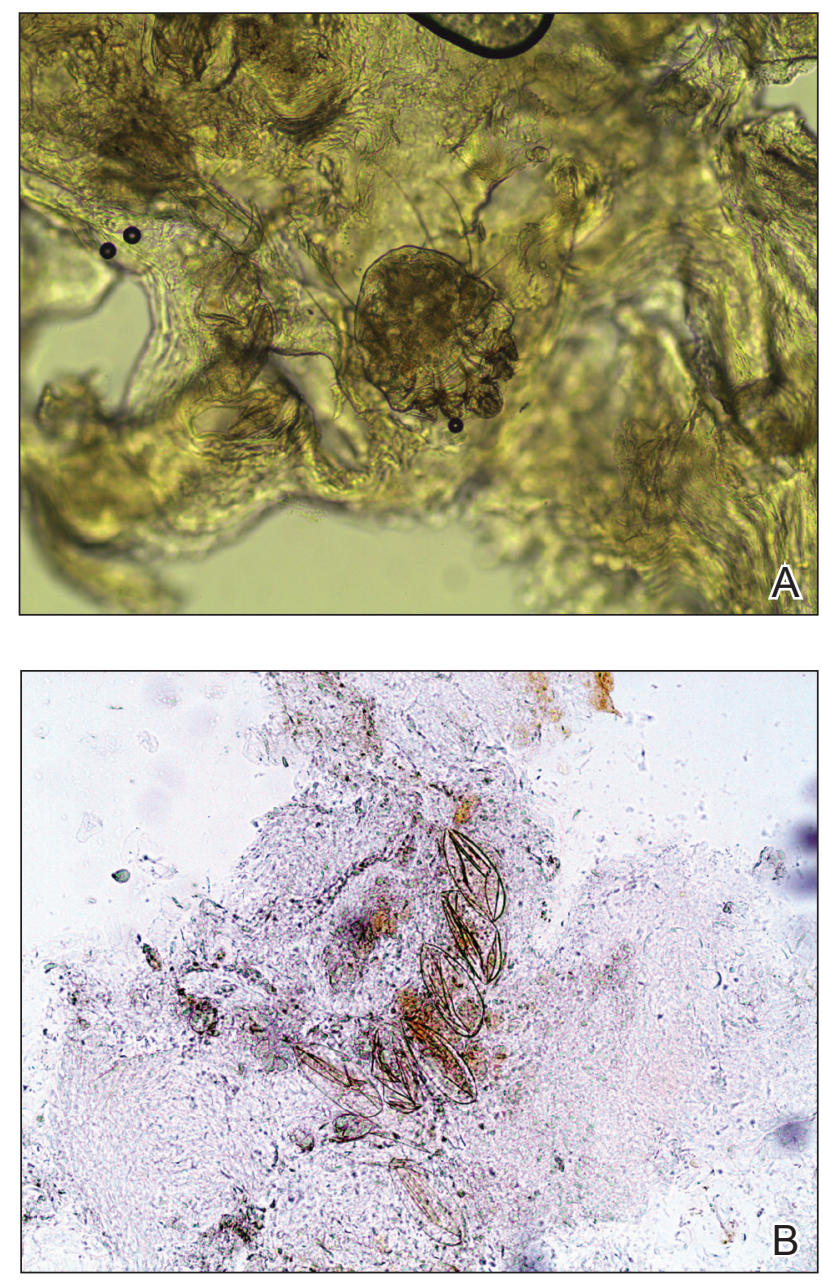

FIGURE 2. A and B, Wet mount with potassium hydroxide $20 \%$ showing a Sarcoptes scabiei var hominis mite and mite eggs (original magnifications $\times 40$ ). scabies, skin burrows and pruritus may be minimal or absent, thus making the diagnosis of crusted scabies more difficult than normal scabies. ${ }^{6}$ Diagnosis of crusted scabies is confirmed by direct microscopy, which demonstrates mites, eggs, or feces. Strict isolation of the patient is necessary, as the disease is very contagious. Treatment with oral ivermectin (1-3 doses of $3 \mathrm{mg}$ at 14-day intervals) in combination with topical permethrin is effective. ${ }^{7}$

We present a case of crusted scabies with nail involvement that presented with white superficial onychomycosislike lesions. The patient's nails were successfully treated with a combination of oral ivermectin and topical permethrin occlusion of the nails. In cases with subungual hyperkeratosis, nonsurgical nail avulsion with $40 \%$ urea cream or ointment has been used to improve the penetration of permethrin. Partial nail avulsion may be necessary if subungual hyperkeratosis or nail dystrophy becomes extreme. ${ }^{8}$

\section{REFERENCES}

1. Danielsen DG, Boeck W. Treatment of Leprosy or Greek Elephantiasis. JB Balliere; 1848.

2. Parish L, Lumholt G. Crusted scabies: alias Norwegian scabies. Int J Dermatol. 1976;15:747-748.

3. Centers for Disease Control and Prevention. Parasites: scabies. Updated November 2, 2010. Accessed January 17, 2021. https://www.cdc.gov /parasites/scabies/

4. Roberts LJ, Huffam SE, Walton SF, et al. Crusted scabies: clinical and immunological findings in seventy-eight patient and a review of the literature. J Infect. 2005;50:375-381.

5. Dourmisher AL, Serafimova DK, Dourmisher LA, et al. Crusted scabies of the scalp in dermatomyositis patients: three cases treated with oral ivermectin. Int J Dermatol. 1998;37:231-234.

6. Barnes L, McCallister RE, Lucky AW. Crusted (Norwegian) scabies: occurrence in a child undergoing a bone marrow transplant. Arch Dermatol. 1987;123:95-97.

7. Huffam SE, Currie BJ. Ivermectin for Sarcoptes scabiei hyperinfestation. Int J Infect Dis. 1998;2:152-154.

8. De Paoli R, Mark SV. Crusted (Norwegian) scabies: treatment of nail involvement. J Am Acad Dermatol. 1987;17:136-138. 